\title{
Editorial
}

\section{La Cultura de Paz en Nicaragua}

Denis Torres*

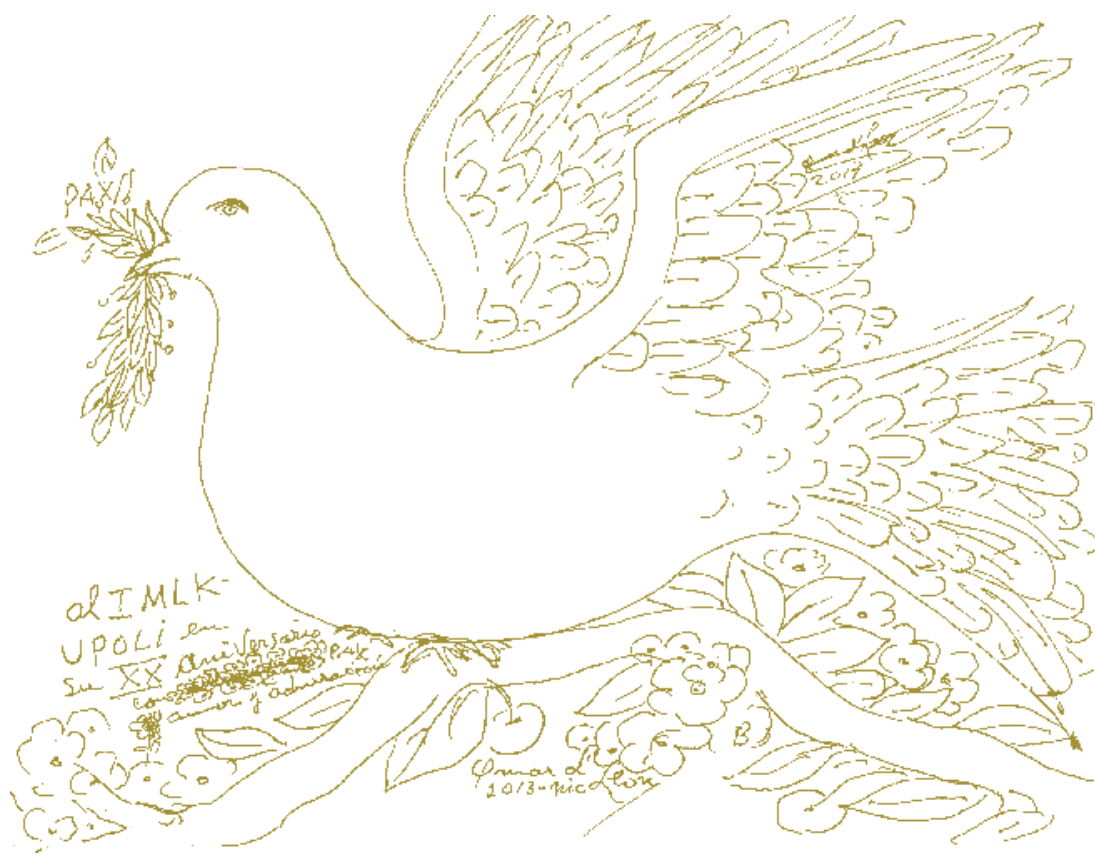

A poco más de dos décadas del cese de la guerra, cabe preguntarse si la paz alcanzada en Nicaragua se orienta a la construcción de una cultura de paz.

La cultura de paz se entiende como un conjunto de valores, actitudes, tradiciones, comportamientos y estilos de vida basados en: a) El respeto a la vida, el fin de la violencia y la promoción y la práctica de la no violencia por medio de la educación, el diálogo y la cooperación; b) El respeto pleno de los principios de soberanía, integridad territorial e independencia política de los Estados y de no injerencia en los asuntos que son esencialmente jurisdicción interna de los Estados, de conformidad con la Carta de las Naciones Unidas y el derecho internacional; c) El respeto pleno y la promoción de todos los derechos humanos y las libertades fundamentales; d) El compromiso con el arreglo pacífico de los conflictos; e) Los esfuerzos para satisfacer las necesidades de desarrollo y protección del medio ambiente de

\section{RESUMEN}

A partir de elementos tales como: el desarrollo de una mentalidad democrática en la clase política, el desarrollo institucional y constitucional, diversas expresiones organizativas de la sociedad civil, se muestra un incipiente pero importante cambio cultural en Nicaragua, favorable al desarrollo de una cultura de paz.

Palabras clave: Elecciones, derechos humanos, educación, violencia.

\section{ABSTRACT}

An incipient but important cultural change in Nicaragua in favor of development a culture of peace is demonstrated as of items such as: the development of a democratic mentality in political class, institutional and constitutional development, and different organizational representations of civil society.

Key words: elections, human rights, education, violence,

* Director del Instituto "Martin Luther King" de la Universidad Politécnica de Nicaragua (UPOLI). 
las generaciones presente y futuras; f) El respeto y la promoción del derecho al desarrollo; g) El respeto y el fomento de la igualdad de derechos y oportunidades de mujeres y hombres; $h$ ) El respeto y el fomento del derecho de todas las personas a la libertad de expresión, opinión e información; i) La adhesión a los principios de libertad, justicia, democracia, tolerancia, solidaridad, cooperación, pluralismo, diversidad cultural, diálogo y entendimiento a todos los niveles de la sociedad y entre las naciones; $\mathrm{y}$ animados por un entorno nacional e internacional que favorezca a la paz (ONU A/RES/53/243).

De acuerdo a lo anterior, el desarrollo de una cultura de paz no es fácilmente cuantificable, medible, en una sociedad, puesto que no existen indicadores como los hay por ejemplo para medir el crecimiento y desarrollo económico, pues se ubica en el terreno de los cambios culturales, de las mentalidades, actitudes, de lo intangible, sin embargo, es posible identificar signos que indican, aunque de manera incipiente y contradictoria, un cierto avance en esa dirección.

1. Para comenzar, podemos afirmar que este cambio cultural, se refleja en el incipiente paso de una cultura de violencia, intolerancia y exclusión, a una nueva práctica y a un nuevo pensamiento en la clase política nicaragüense que históricamente ha gravitado de manera decisiva en la historia ensangrentada de nuestra patria.

Es perceptible que el lenguaje bélico, explicable en una sociedad que ha vivido una historia de guerras y confrontación hasta hace poco más de 20 años, va cambiando por un lenguaje que hace referencia más al diálogo, el consenso, la concertación; nuevos conceptos como la unidad en la diversidad, una práctica negociadora, de mediación y abordaje pacífico de los conflictos, consolidándose el hecho electoral como uno de los instrumentos para dirimir los diferentes proyectos políticos existentes. Aunque, como un signo contradictorio, en las últimas contiendas electorales, los poderes fácticos -partidos, aparatos gubernamentales y estaduales- han utilizado el clima de paz para reprimir violentamente a sus adversarios, impedir su libre movilización y derecho a protestar. El poder político en Nicaragua ha desarrollado una práctica de cooptación de instituciones del Estado para ponerlas al servicio de sus objetivos. Tendencia que, de continuar, se transformará inevitablemente en un factor de inestabilidad y de violencia recurrentes.

Pese a lo anterior, la clase política nicaragüense desde los años 90, ha venido desarrollando acuerdos, diálogos políticos, pactos, esquemas de concertación económica social, como otra forma de hacer política, además del acontecimiento propiamente electoral.

2. Ha habido un incremento sensible en el desarrollo y coordinación de las organizaciones de la sociedad civil que luchan contra la violencia a la mujer y la niñez, así como un mayor desarrollo de un enfoque de género que cuestiona las concepciones y prácticas patriarcales en la sociedad, las cuales se desarrollan en el seno familiar, la escuela, el ámbito laboral, la comunidad y en los aparatos ideológicos. La lucha por la igualdad de derechos de la mujer, por una sociedad donde prime la equidad de género y los logros históricos alcanzados en el terreno jurídico e institucional es una realidad en Nicaragua.

3. Una cultura de los derechos humanos se viene abriendo paso, entre otros factores con: la creación de la Defensoría del Pueblo o Procuraduría para la Defensa de los Derechos Humanos; la existencia de organizaciones beligerantes en la sociedad civil que trabajan por la promoción y defensa de los derechos humanos; la enseñanza de los derechos humanos en los dos niveles del sistema educativo, primario y secundario, establecido por ley, aunque este contenido de la Cultura de Paz se aborda con serias limitaciones en su profundidad, actualización, metodologías, etc. Se han desarrollado importantes programas de capacitación en derechos humanos a través de la educación no formal a sectores estratégicos de la sociedad: minorías étnicas, mujeres, policía, medios de comunicación, etc. En esta labor participan todo un tejido de organizaciones de la sociedad civil. Logros en este sentido se refleja en leyes vigentes en contra de la violencia a la mujer y la niñez, el Código de la Familia, los derechos de la Madre Tierra, los derechos de las poblaciones originarias, de los colectivos LGTB, entre otros.

4. En las universidades se han venido instaurando cátedras de educación para una Cultura de la Paz, 
lo cual incluye nuevos contenidos propios del paradigma: gestión pacífica de conflictos, derechos humanos, formación integral, enfoque de género, cultura de paz, educación ambiental. En el subsistema de educación superior, al menos diez universidades imparten la asignatura de Cultura de Paz de las 42 existentes en el país.

5. Es evidente los cambios operados en el conjunto de las fuerzas armadas nicaragüenses, las cuales han pasado de ser instituciones partidarizadas, fruto del origen de las mismas a ser instituciones profesionales, modernizadas y actualizadas en el contexto de los cambios operados en el mundo y en la región. Es el caso del Ejército, del EPS, hoy Ejército Nacional, que además de su función fundamental de salvaguarda de la soberanía nacional y la integridad territorial, desarrolla funciones contra el narcotráfico y el crimen organizado, así como una incipiente participación en la defensa del medioambiente.

6. La sociedad ha sido testigo de un proceso de cambio del accionar policial en el desempeño de sus funciones, haciendo uso creciente de métodos como el diálogo, la persuasión, incluso la mediación, así como el gradual y proporcional uso de la fuerza en el abordaje de los conflictos. Cabe mencionar que en Nicaragua a diferencia de otros países, la violencia delictiva que es la nueva forma de violencia que se vive, además de la violencia hacia la mujer, es abordada con enfoque preventivo y proactivo, apoyándose en la participación de la comunidad y brindando condiciones para la reinserción social de los grupos juveniles transgresores. Ello, aún cuando la tentación represiva ha estado presente en últimos acontecimientos sociales y políticos.

7. Aún cuando, en particular desde los años 90, se han desarrollado organizaciones ambientalistas en la sociedad civil,muy pocoseha avanzadoenestecampo, pues ni siquiera el Estado ha estado a la altura de sus responsabilidades y compromisos internacionales. Sin embargo, el paradigma medioambiental ha venido poco a poco desarrollándose en la conciencia colectiva y es un contenido incipiente y débil de enseñanza en el sistema educativo.
8. Una política exterior de paz, con énfasis en la observancia del derecho internacional y el diálogo en nuestras relaciones internacionales.

9. El combate a la pobreza. Causa estructural de muchas formas de violencia.

Cabe mencionar en el contexto de esta breve reseña, algunas instituciones y personalidades que vienen contribuyendo al desarrollo de una cultura de paz en Nicaragua desde sus diferentes ámbitos:

Instituciones: UPOLI, a través de su Instituto "Martin Luther King", UNAN-Managua, UNAN-León, UNI, UNA, UCA, IDEUCA, U de M, Universidad del Valle, UNICA, UNESCO, MINED, Hogar Zacarías Guerra, Consejo Nacional de la Juventud, Casa Alianza, Red de Mujeres contra la Violencia, Movimiento de Mujeres "María Elena Cuadra", Movimiento Comunal de Nicaragua, Policía Nacional, Ejército de Nicaragua, Centro de Estudios Internacionales (CEI), Centro de Prevención de la Violencia (CEPREV), Instituto para el Desarrollo de la Democracia (IPADE), Dúo Guardabarranco, Puntos de Encuentro.

Personalidades: Carlos Tünnermann B., Juan Bautista Arríen, Alejandro Serrano Caldera, Padre Miguel d' Escoto, Cardenal Miguel Obando Bravo, Anastasio Lovo, Erwin Silva, Soren Chamorro, Denis Torres, Bianca Jagger, Vilma Núñez de Escorcia, Francisco Lacayo Parajón, Zoilamérica Ortega, Ana Criquillón, Norman Bent, Sergio Denis García, Mónica Zalaquett, Carlos Emilio López, Sandra Ramos, Mauricio Zúniga, Katia Cardenal, Carlos Mejía Godoy, Luis Enrique Mejía Godoy, José Miguel Torres (q.e.p.d), Gustavo Parajón (q.e.p.d), Salvador Cardenal (q.e.p.d).

Estos son algunos elementos que dan cuenta de signos esperanzadores en el lento, difícil, contradictorio y complejo desarrollo de una cultura de paz en nuestro país, lo cual demuestra que un cambio cultural no se produce por decreto, sino que es un largo proceso en donde interactuamos todos los actores de la sociedad.

Managua, mayo 2013. 